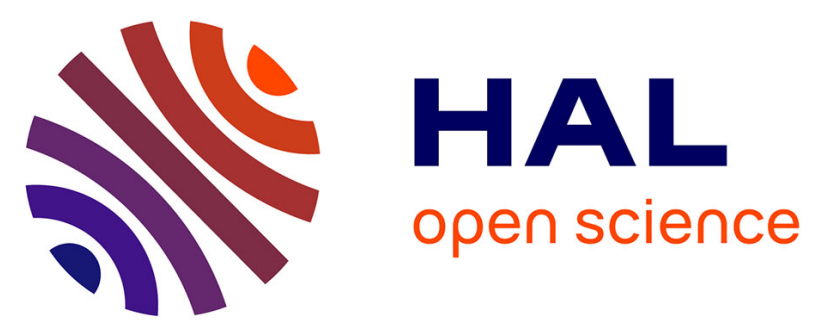

\title{
Reciprocal and Self-Aging Effects of Power Components on Reliability of DC-DC Boost Converter With Coupled and Decoupled Thermal Structures
}

Vahid Samavatian, Hossein Iman-Eini, Yvan Avenas, Soudabeh Shemehsavar

\section{- To cite this version:}

Vahid Samavatian, Hossein Iman-Eini, Yvan Avenas, Soudabeh Shemehsavar. Reciprocal and SelfAging Effects of Power Components on Reliability of DC-DC Boost Converter With Coupled and Decoupled Thermal Structures. IEEE Transactions on Components, Packaging and Manufacturing Technology, 2019, 9 (12), pp.2506-2513. 10.1109/TCPMT.2019.2940058 . hal-02509488

\section{HAL Id: hal-02509488 \\ https://hal.science/hal-02509488}

Submitted on 17 May 2021

HAL is a multi-disciplinary open access archive for the deposit and dissemination of scientific research documents, whether they are published or not. The documents may come from teaching and research institutions in France or abroad, or from public or private research centers.
L'archive ouverte pluridisciplinaire HAL, est destinée au dépôt et à la diffusion de documents scientifiques de niveau recherche, publiés ou non, émanant des établissements d'enseignement et de recherche français ou étrangers, des laboratoires publics ou privés. 


\title{
Reciprocal and Self-Aging Effects of Power Components on Reliability of DC-DC Boost Converter with Coupled and Decoupled Thermal Structures
}

\author{
V. Samavatian, H. Iman-Eini, Senior Member, IEEE and Y. Avenas, S. Shemehsavar
}

\begin{abstract}
Reliable and unceasing exploitation of power electronic converters plays a major part in numerous applications. The aging effects on the performance of a DC-DC boost power converter with different thermal structures is under consideration in this study. This paper demonstrates the feasibility of using sensitivity analysis for a much more accurate estimation in the power converters' performances. This paper deals with a DC-DC boost converter as a case study in two thermal structures (coupled and decoupled) for electric vehicle application. Significant self and reciprocal effects of components can thoroughly impress the reliability assessment in the thermal coupled structure. It reveals that the useful lifetime of IGBT and diode can decrease by $35 \%$ and $44 \%$, respectively. It is while that in the thermal decoupled structures, there are not significant reciprocal effects neither in electrical or thermal operating points. The results reveal the importance of reciprocal aging and self-aging effects on the reliability assessment in the coupled thermal structure.

Index Terms - Interval Analysis, Power converter, Reliability, Reliability Assessment, Thermal loading, Thermal modeling.
\end{abstract}

\section{INTRODUCTION}

$\mathrm{R}$ ELIABILITY of power electronic converters has gained importance in recent years $[1,2]$. In the last few years, there has been a growing interest in the physics of failure (PoF) based reliability assessment of power electronic devices in different applications [3]-[5]. From the literature, the power capacitors and semiconductors are the most vulnerable parts in power converters and consequently play major roles in their reliability [5].

In the field of power semiconductor devices, thermomechanical fatigue failure mechanism is important because of the junction temperature swings and coefficient of thermal expansion (CTE) mismatch between the different laminated layers [6, 7]. Accordingly, by applying heat to the chip owing to the mismatch of the CTEs of the layers and bond wires, thermo-mechanical stresses are induced between them leading to their degradations. The degradations have been indicated by increases in on-state voltage and junction to case thermal resistance as well [8, 9]. Additionally because of capacitor voltage and ripple current stresses, the most critical failure mechanism in capacitors is dielectric loss leading to capacitors' parameters drifting (capacitance and dissipation factor) [10].

These degradations have knock-on effects on the global performance of converters and make changes either in electrical or thermal operating points (EOP/TOP) leading to more accelerated degradations. Assume a part of power converter

V. Samavatian is with the School of Electrical and Computer Engineering, College of Engineering, University of Tehran, Tehran, Iran and the Univ. Grenoble Alpes, CNRS, Grenoble INP (Institute of Engineering Univ. Grenoble Alpes), G2Elab, 38000 Grenoble, France (e-mail: vahidsamavatian@ut.ac.ir).

$\mathrm{H}$. Iman-Eini is with the School of Electrical and Computer Engineering, College of Engineering, University of Tehran, Tehran, Iran (e-mail: imaneini@ut.ac.ir). containing two power semiconductors and a capacitor. Fig. 1 shows the links between the different aspects (thermal and electrical environment) and parameters of this part for reliability assessment [11]. As previously mentioned, degradations of the components can affect the others. For example, assume that power semiconductor \#1 has been degraded and its junction-case thermal resistance $\left(\mathrm{R}_{\mathrm{th} \# 1}\right)$ as well as its voltage $\left(\mathrm{V}_{\# 1}\right)$ increase. By an increase in $\mathrm{R}_{\mathrm{th}}$, the junction temperature of $\# 1$ would be changed and consequently its temperature dependent electrical parameters would also be changed resulting in the new EOP and TOP. In the same procedure by an increase in $\mathrm{V}_{\# 1}$, EOP and consequently TOP (via power loss model) would be changed. New electrical operating point can affect useful lifetime of capacitor, while both EOP and TOP can affect power semiconductor \#2 and also \#1. Therefore, it is evident that how the degradation of one component can influence and accelerate the aging of the other components and the global system.

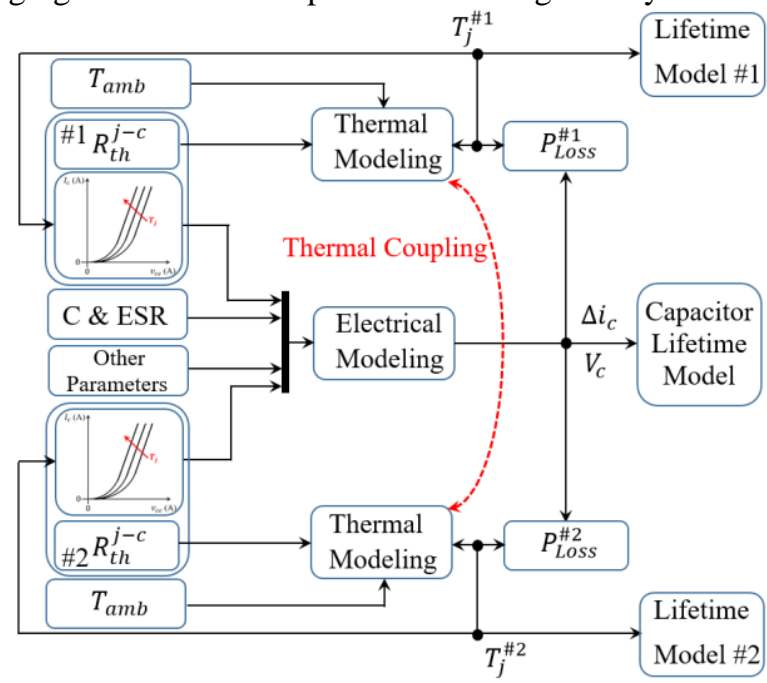

Fig. 1. Thermal and electrical reliability correlations for a sample part in power converter including two power semiconductors and a capacitor [11]

Most of the previous studies have not yet taken into account the degradation of circuit components and their effects on the other components. The thrust of authors' argument is to consider the reciprocal- and self-aging effects of the components on the reliability of the conventional boost DC-DC converter as a case study in two different thermal structures. This study is the supplementary research of our previous research [11] and mainly

Y. Avenas is with the Univ. Grenoble Alpes, CNRS, Grenoble INP (Institute of Engineering Univ. Grenoble Alpes), G2Elab, 38000 Grenoble, France (e-mail: yvan.avenas@g2elab.grenoble-inp.fr).

S. Shemehsavar is with the school of Mathematics and Statistics and Computer Science, University of Tehran, Tehran, Tehran (Shemehsavar@khayam.ut.ac.ir) 
focuses on the effects of thermal structures on the reliability of power converters. The proceeding sections outline the proposed rationale of PoF based reliability assessment and its application to the conventional DC-DC boost converter through thermal modeling and sensitivity analysis. Finally, lifetime estimation of this converter as an interface between battery bank and motor driver in an electric vehicle application will be discussed.

\section{INVESTIGATION ON SELF- AND RECIPROCAL DEGRADATION EFFECTS}

Degradations of power components have been indicated by parameters drifting and consequently led to affect EOP and TOP. Since, reliability of a power converter is absolutely EOP and TOP dependent (due to the inherent of critical failure mechanisms), parameter deviations make a significant contribution in reliability assessment. This section deals with the effects of aging on the TOP and EOP of the conventional DC-DC boost converters.

\section{A. Degradation of converter}

By passing time IGBT, diode and capacitor would be degraded resulting in parameters' drifting. As shown in Fig. 1, these parameters drifs can change electrical and thermal operating points leading to accelerated aging. For considering the influences, five following cases are defined:

Case I, in this case all the devices including IGBT, diode and capacitor are new and have their own nominal parameters.

Case II, in this case (aged case) all the devices including IGBT, diode and capacitor have been degraded and reached to their failure criterion describing in the following cases.

Case III, in this case IGBT has been electrically and thermally degraded while all the other components have been unchanged. It assumes that junction to case thermal resistance of IGBT increases by $20 \%$ [12] and reaches $1.38^{\circ} \mathrm{C} / \mathrm{W}$ and collectoremitter voltage increases by $20 \%[12,13]$.

Case $I V$, in this case diode has been electrically and thermally degraded while all the other components have been unchanged. It assumes that junction to case thermal resistance of IGBT increases by $20 \%$ and reaches $2.28^{\circ} \mathrm{C} / \mathrm{W}$ and forward voltage increases by $20 \%$.

Case $V$, in this case output capacitor has been degraded while all the other components have been unchanged. It assumes that capacitance decreases by $20 \%$ and reaches to $38 \mu \mathrm{F}$ and equivalent series resistor (ESR) increases by $200 \%$ and reaches $100 \mathrm{~m} \Omega[10]$.

\section{B. Power converter modeling}

The schematic of this converter is shown in Fig. 2. All the parameters are defined in this figure. Both IGBT and diode can be modeled by a series circuit including an ideal switch, an internal resistor and an internal forward voltage when they are in on-state. The IGBT and the diode are made with the same device (IKP15N60T). For the considered boost DC-DC converter, working conditions and parameters are listed in Table 1. Capacitor useful lifetime is directly dependent on its voltage and current ripple. Moreover, junction temperatures of IGBT and diode also depends on their power losses being affected by IGBT/diode voltage and current ripple stresses. Therefore, an electrical modeling capable of accurately analyzing voltage and current ripples seems to be necessary. Among various approaches
Table 1. Working Conditions and Parameters Values

\begin{tabular}{|c|c|c|c|}
\hline Parameter & Value & Parameter & VALUE \\
\hline$V_{i}$ & $200 \mathrm{~V}$ & $V_{\text {out }}$ & $400 \mathrm{~V}$ \\
\hline$P_{o}$ & $3000 \mathrm{~W}$ & $R$ & $53.34 \mathrm{Ohm}$ \\
\hline$f_{S}$ & $20 \mathrm{kHz}$ & & \\
\hline$L$ & $2.5 \mathrm{mH}$ & $r_{L}$ & $0.3 \mathrm{Ohm}$ \\
\hline$C$ & $47 \mu \mathrm{F}$ & $r_{C}$ & $0.05 \mathrm{Ohm}$ \\
\hline$r_{D}$ & 0.04 Ohm @ $\mathrm{T}_{\mathrm{j}}=175^{\circ} \mathrm{C}$ & $V_{D O}$ & $1 \mathrm{~V} @ \mathrm{~T}_{\mathrm{j}}=175^{\circ} \mathrm{C}$ \\
\hline$r_{Q}$ & $0.0726 \mathrm{Ohm} @ \mathrm{~T}_{\mathrm{j}}=175^{\circ} \mathrm{C}$ & $V_{C E O}$ & $0.81 \mathrm{~V} @ \mathrm{~T}_{\mathrm{j}}=175^{\circ} \mathrm{C}$ \\
\hline
\end{tabular}

for analyzing the state space equations of boost DC-DC converter $[14,15]$, time invariant multi frequency (TIMF) analysis is selected [15]. This approach is based on the Fourier series and let the coefficient of Fourier series be the state variables of the interested system. If higher order Fourier series (N) was under study, more accurate modeling would be achieved. This approach has lots of advantages including easy construction, capable of considering feedback and accurate ripple estimation which is thoroughly necessary for both capacitor degradation assessment and power losses calculation in power semiconductor devices. Not giving an exhaustive detail of TIMF, interested readers are referred to [16].

The main procedure of specified device power loss calculation has been always launched by its manufacturer. Power losses in the IGBT and the diode can be expressed as the sum of the conduction and switching losses giving:

$$
\begin{aligned}
& \mathrm{P}_{\text {Loss }}^{\mathrm{IGBT}}=\mathrm{P}_{\mathrm{CQ}}\left(\mathrm{T}_{\mathrm{j}}\right)+\mathrm{P}_{\text {onsQ }}\left(\mathrm{T}_{\mathrm{j}}\right)+\mathrm{P}_{\text {offsQ }}\left(\mathrm{T}_{\mathrm{j}}\right) \\
& \mathrm{P}_{\text {Loss }}^{\text {Diode }}=\mathrm{P}_{\mathrm{CD}}\left(\mathrm{T}_{\mathrm{j}}\right)+\mathrm{P}_{\mathrm{SD}}\left(\mathrm{T}_{\mathrm{j}}\right)
\end{aligned}
$$

where $\mathrm{P}_{\mathrm{CQ}}$ and $\mathrm{P}_{\mathrm{SQ}}$ are conduction and switching power losses of IGBT and $P_{D Q}$ and $P_{D Q}$ are conduction and switching power losses of diode. IGBT and diode power losses are both temperature dependent and therefore they must be calculated by iterative algorithm till they are converged. Using electrical and thermal parameters in case I, the power losses in IGBT and diode are 30.74 and $14.13 \mathrm{~W}$, respectively. In case II, power losses in IGBT and diode are 35.9 and $17.39 \mathrm{~W}$, respectively. It is worth mentioning that aged power losses had been used for heat sink design in both structures.

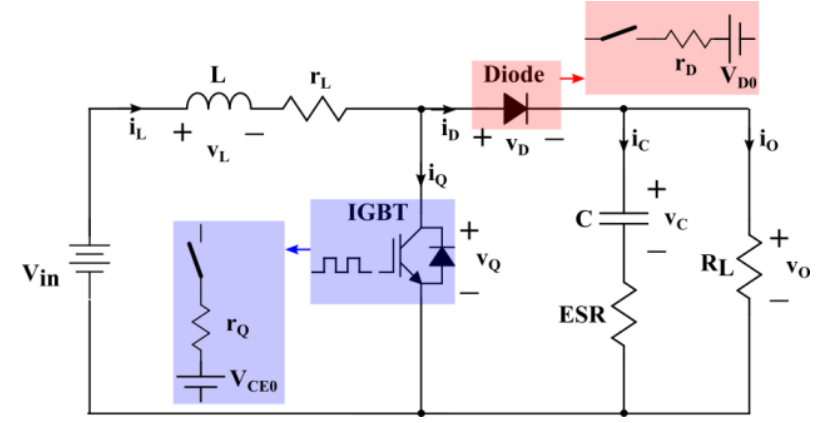

Fig. 2. Boost DC-DC power converter.

Thermally, there are two possible structures for this converter. Of course, for expressing the importance of self and reciprocal effects consideration in this study, both following structures have been taken into account. Plate-fin heat sink in forced convection heat transfer condition has been designed and employed for both structures with the length, width and height of $60 \mathrm{~mm}, 55 \mathrm{~mm}$ and $40 \mathrm{~mm}$, respectively. It has to be mentioned that junction-case thermal resistances of IGBT and diode are $1.15^{\circ} \mathrm{C} / \mathrm{W}$ and $1.9^{\circ} \mathrm{C} / \mathrm{W}$, respectively. Thermal resistance of thermal interface material $\left(\mathrm{R}_{\mathrm{th}(\mathrm{c}-\mathrm{h})}\right)$ is measured to be $0.5^{\circ} \mathrm{C} / \mathrm{W}$ for both structures. 
Structure I, Both IGBT and diode are mounted on the common heat sink. Its physical perspective and steady state thermal equivalent circuit is depicted in Fig. 3a. Based on the power loss of IGBT and diode ( $36 \mathrm{~W}$ and $17.4 \mathrm{~W}$ in case II), the conventional static thermal equivalent circuit model, the maximum allowed junction temperature $\left(170^{\circ} \mathrm{C}\right)$ and the ambient temperature $\left(40^{\circ} \mathrm{C}\right)$, one can easily calculate thermal resistance of heat sink to the ambient equaling to $1.16^{\circ} \mathrm{C} / \mathrm{W}$. Air velocity was fixed to $8 \mathrm{~m} / \mathrm{s}$ to reach this value by fan voltage adjustment.

Structure II, IGBT and diode are mounted on two separate heat sinks. Their physical perspectives and steady state thermal equivalent circuits are depicted in Fig. 3b. Based on the power loss of IGBT and diode ( $36 \mathrm{~W}$ and $17.56 \mathrm{~W}$ in case II) and previous mentioned conditions, one can easily calculate the thermal resistances of both heat sinks to the ambient equaling to $1.92^{\circ} \mathrm{C} / \mathrm{W}$ and $4.62^{\circ} \mathrm{C} / \mathrm{W}$ in IGBT and diode, respectively. Air velocity was fixed to $3 \mathrm{~m} / \mathrm{s}$ and $0.25 \mathrm{~m} / \mathrm{s}$ to reach these values for IGBT and diode, respectively.
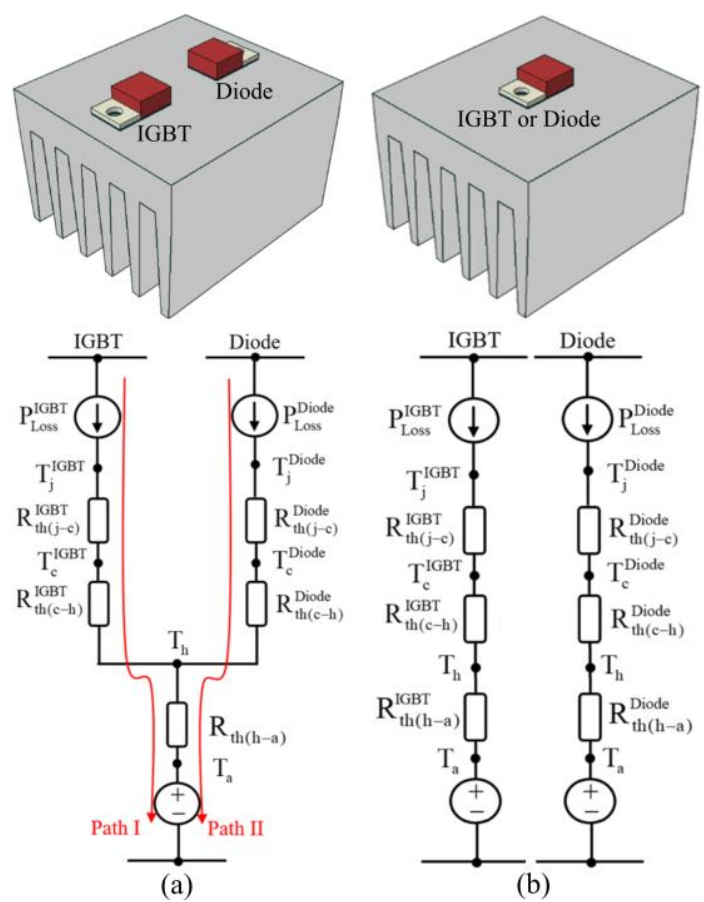

Fig. 3. Steady state thermal equivalent circuit, (a) Structure I, (b) Structure II.

With regard to the critical failure mechanism (thermo mechanical fatigue), thermal modeling plays a major role in lifetime estimation of power semiconductors [17]-[19].

Therefore, a complete dynamic thermal model considering the thermal coupling effects is employed and applied to our problem. Following matrix equation should be solved after estimating all of its elements by performing finite element analysis via ABAQUS environment.

$$
\left[\begin{array}{c}
\mathrm{T}_{\mathrm{j}}^{\mathrm{IGBT}} \\
\mathrm{T}_{\mathrm{j}}^{\text {Diode }}
\end{array}\right]=\left[\begin{array}{cc}
\mathrm{Z}_{\text {IGBT }} & \mathbf{Z}_{\text {IGBT-Diode }} \\
\mathbf{Z}_{\text {Diode-IGBT }} & \mathrm{Z}_{\text {Diode }}
\end{array}\right]\left[\begin{array}{l}
\mathrm{P}_{\text {Loss }}^{\mathrm{IGBT}} \\
\mathrm{P}_{\text {Loss }}^{\text {Diode }}
\end{array}\right]+\mathrm{T}_{\mathrm{a}}
$$

For obtaining the thermal impedance matrix elements in equation (2), one can use the superposition theory [20]. Accordingly, one can easily calculate both self and cross coupling thermal impedances. The simulation details have been discussed in [11]. From these simulations, both self and cross coupling thermal impedances have been derived. The thermal impedances
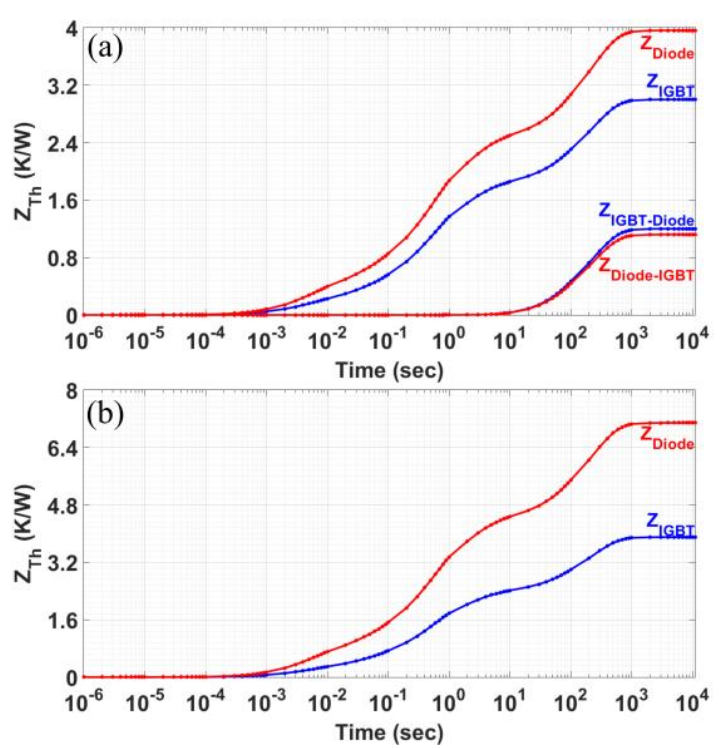

Fig. 4. Thermal resistance matrix elements for (a) structure I, (b) structure II.

are shown in Fig.4. Fig. 4a (both devices are on the same heat sink) depicts the thermal impedances for structure I. Fig. $4 \mathrm{~b}$ (two devices are on the separated heat sinks) depicts the thermal impedances for structure II.

\section{Sensitivity Analysis}

Due to the aging, electrical and thermal parameters deviations can affect the reliability assessment. Therefore, one should investigate whether or not these deviations can influence reliability evaluation. Regarding considered failure mechanisms, the question is that how electrical and thermal parameters deviations can affect the electrical and thermal operating points of the considered boost DC-DC converter.

In this section among lots of qualitative sensitivity analysis [21], a quantitative sensitivity analysis, namely interval analysis (IA), has been employed [22]. This method has been extensively employed in digital numerical computation [23]. However, it has become an attractive quantitative-sensitivity analysis and solver of nonlinear problems among researchers and engineers [21]. Interval analysis has numerous advantages including correctness, totality, closedness, optimality and efficiency. Explaining all the above mentioned features is beyond this study and interested readers are referred to [22]. This method is based on the bounded arithmetic which means that every parameter can have not exact value but a bounded interval. This interval can be due to the manufacturing tolerance, aging, and temperature dependency. A closed real interval $\mathrm{x}$ is a set of real numbers defined as follows

$$
\mathrm{X}=[\underline{\mathrm{X}}, \overline{\mathrm{X}}]=\{\mathrm{x} \in \mathrm{R}: \underline{\mathrm{X}} \leq \mathrm{x} \leq \overline{\mathrm{X}}\}
$$

where $\underline{X}$ is the minimum and $\bar{X}$ is the maximum values of parameter $\mathrm{X}$. Now, instead of applying arithmetic operations to the only real numbers, we should apply them to the set of real numbers. For instance, the sum of two intervals results in a new interval containing the sums of all pairs of numbers. Accordingly, the sum of two intervals $X$ and $Y$ is the set given by

$$
\mathrm{X}+\mathrm{Y}=[\underline{\mathrm{X}}+\underline{\mathrm{Y}}, \overline{\mathrm{X}}+\overline{\mathrm{Y}}]=\{\mathrm{x}+\mathrm{y}: \mathrm{x} \in \mathrm{X}, \mathrm{y} \in \mathrm{Y}\}
$$

In electrical engineering, mathematic models of physical phenomena are including either matrix or vector forms. As it was 
mentioned, we used TIMF state space equation (in matrix form). Interval matrix is a matrix whose elements are interval numbers given as follows:

$$
A=\left[\begin{array}{ll}
A_{11} & A_{12} \\
A_{21} & A_{22}
\end{array}\right]=\left[\begin{array}{l}
{\left[\underline{A}_{11}, \bar{A}_{11}\right]\left[\underline{A}_{12}, \bar{A}_{12}\right]} \\
{\left[\underline{A}_{21}, \bar{A}_{21}\right]\left[\underline{A}_{22}, \bar{A}_{22}\right]}
\end{array}\right]
$$

It was mentioned that TIMF modeling of boost DC-DC converter has been employed. It can be possible to apply IA to the state space matrix of the interested converter shown in Fig. 2. Therefore, we would have interval matrix and subsequently all of the electrical and thermal parameters have also interval values.

The important parameters are including semiconductors junction temperatures, their power losses and electrical operation points (efficiency $(\eta)$ and voltage ratio $\left(M_{\vee}\right)$ ). Table 2 and Table 3 list the results of the interval analysis in the five cases of section II.A for both investigated structures. It is obviously seen from Table. 3 that aging of either IGBT or diode can play a significant role in reliability assessment of boost DC-DC converter. For example, the aging of IGBT leads to $6^{\circ} \mathrm{C}(6.2 \%)$ increase in Diode junction temperature. On the other side, the aging of diode leads to $5.5^{\circ} \mathrm{C}$ $(4.3 \%)$ increase in IGBT junction temperature.

Another important aspect revealed in Table 2 is the selfdegradation effects. Self-degradations significantly influence thermal operating point. For example, simultaneous degradation of IGBT and diode (case II) has led to $25.5^{\circ} \mathrm{C}(25 \%)$ and $24.2{ }^{\circ} \mathrm{C}$ $(28 \%)$ increase in IGBT and diode junction temperatures respectively.

Last but not least, the electrical operating point, namely efficiency and voltage ratio, remains approximately constant during all of the components' aging. For this case study, accordingly, one can consider the electrical modeling unchangeable during the aging. This fact can absolutely simplify the reliability assessment.

It can be drawn that capacitor aging either capacitance decrease or equivalent series resistance increase have not any influence on the converter performance and both electrical and thermal operating points are maintained constant. In this case study, for both structures, the deviations of electrical and thermal operating points are fraction of $1 \%$ and accordingly, it is claimed that capacitor aging cannot influence the circuit performance and does not have any reciprocal effects on the other components.

From Table 3, since aging does not have a significant influence on the electrical operating point, one can find that in structure II, there are no reciprocal effects among all components.

The reason is the thermal decoupling between IGBT and diode. A very small impressions are due to the small change in the electrical operating points. As a consequence, the choice of the heat sink configuration has a huge influence on the global reliability.

\section{Experimental validation}

It was expressed that in a converter, the degradations of power components lead to the TOP changes. Accordingly, degradation

Table 2.Parameters Sensitivity for Structure 1 (one heat sink for both devices)

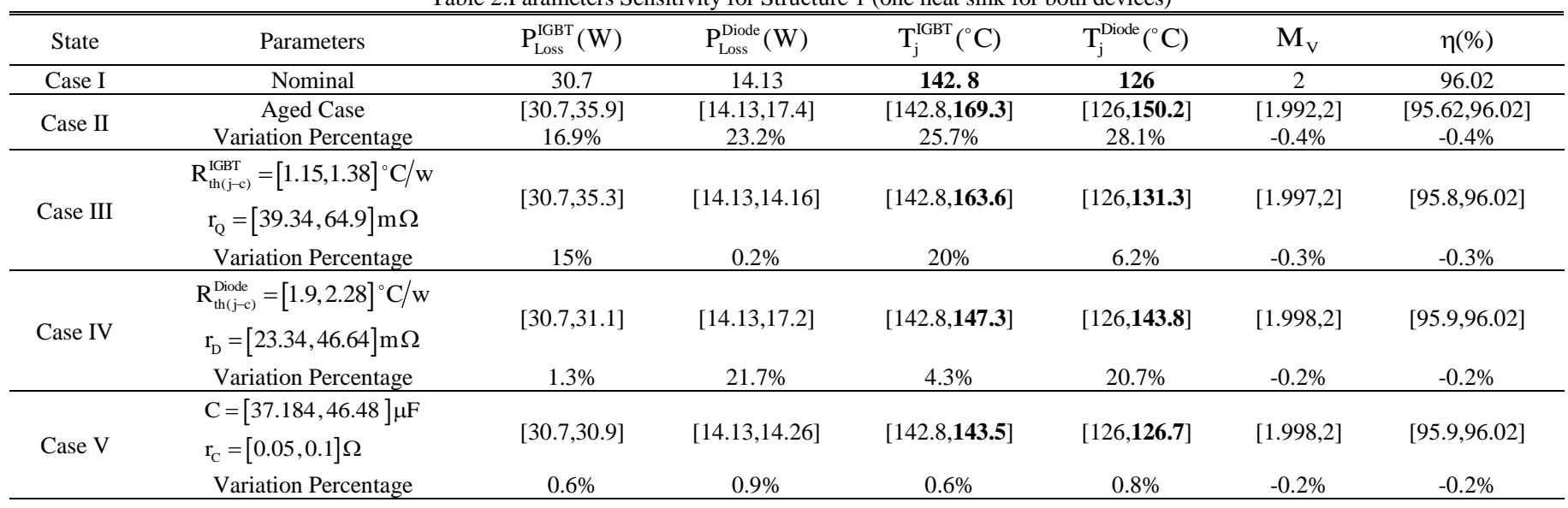

Table 3. Parameters Sensitivity for Structure II (one heat sink for each device)

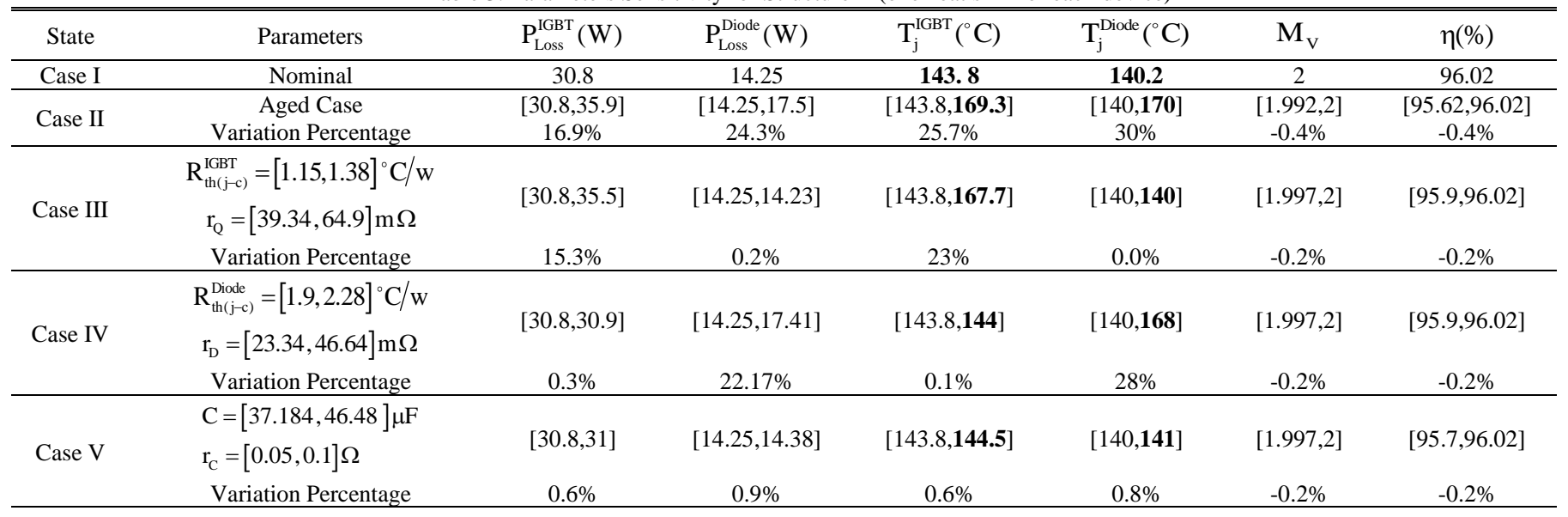


of one device can have effect on the thermal and/or electrical performance of other devices. It means that not only does the degradation of one device accelerate its aging, but also it accelerates other devices' aging. In this study, for demonstrating the effects of degradations of devices on EOP and TOP a conventional 200/400V and 3000W DC-DC boost converter was considered as a case study (see also Table 1 for detailed specifications).

Fig. 5 demonstrates a customized conventional DC-DC boost converter. This converter was designed to monitor junction temperature of power semiconductors in the real time for indicating and proving TOP changes during aging. Fig. 5 shows the schematic of this converter. Two power auxiliary switches and two low power switches are also included. There are also two low current sources $(22.5 \mathrm{~mA})$ for junction temperature measurement by thermo electrical sensitive parameters (TSEP). For the characterization step, the converter is first working under normal condition for a period of time (20 30 min) to be thermally stabilized. Then, S2 and S1are turned off and S3 turned on for $1 \mathrm{msec}$. At this time, two bias current sources (I $\left.\mathrm{I}_{\text {mas }}\right)$ are injected to IGBT and diode through S4 and S5, respectively. Then, the on-state voltages are measured by a data logger. Eventually junction temperature of IGBT and power diode are estimated with a look up table (collector emitter and diode forward voltage as a function of their junction temperatures at $22.5 \mathrm{~mA}$ ) [11].

5 sets of 20 tests are considered for IGBT and power diode. To be sure about thermal stabilization, power DC-DC boost converter worked for 20 30 minutes for each set of measurements. After this stabilization, 20 measurements are done for both IGBT and diode. This procedure is repeated for 5 times. Finally, the junction temperatures of IGBT and diode are estimated by averaging this 100 times.

Fig. 6a illustrates the test bench of the customized DC-DC boost

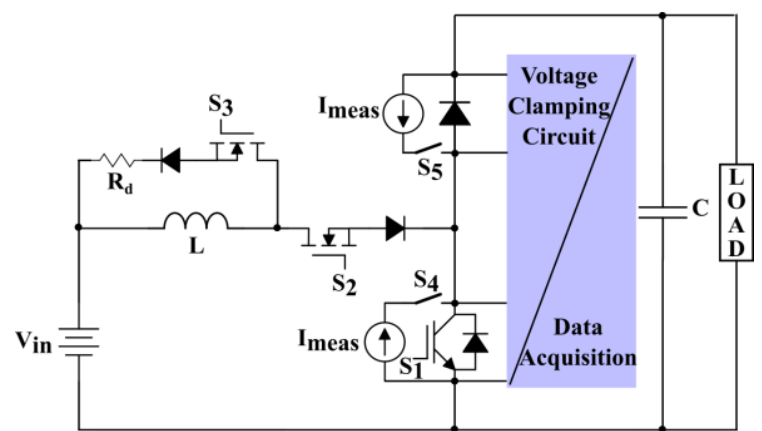

Fig. 5. Conventional DC-DC boost converter equipped with auxiliary circuits.

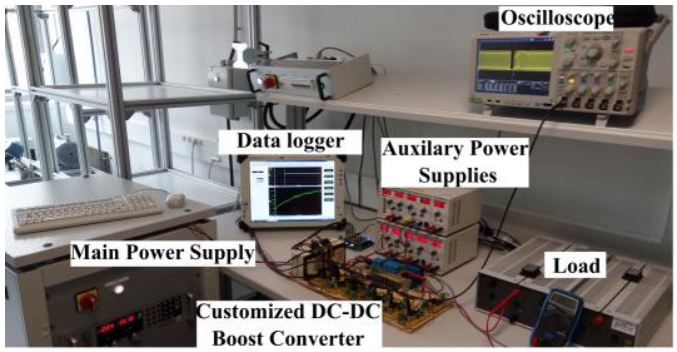

(a)
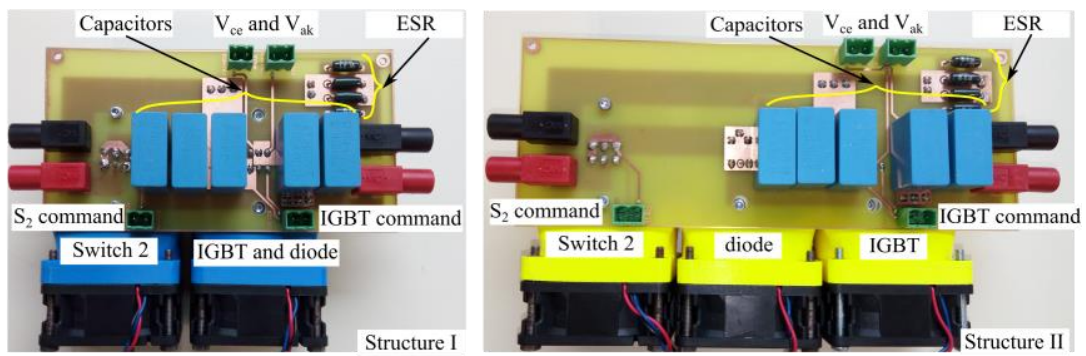

(b)
Table 4. Junction temperature of IGBT and diode

\begin{tabular}{ccccc}
\hline \multirow{2}{*}{ State } & \multicolumn{2}{c}{ Structure I } & \multicolumn{2}{c}{ Structure II } \\
\cline { 2 - 5 } & $\mathrm{T}_{\mathrm{j}}^{\mathrm{IGBT}}\left({ }^{\circ} \mathrm{C}\right)$ & $\mathrm{T}_{\mathrm{j}}^{\mathrm{Diode}}\left({ }^{\circ} \mathrm{C}\right)$ & $\mathrm{T}_{\mathrm{j}}^{\mathrm{IGBT}}\left({ }^{\circ} \mathrm{C}\right)$ & $\mathrm{T}_{\mathrm{j}}^{\text {Diode }}\left({ }^{\circ} \mathrm{C}\right)$ \\
\hline \hline Case I & $\mathbf{1 4 0 . 3}$ & $\mathbf{1 2 2 . 6}$ & $\mathbf{1 4 2 . 2}$ & $\mathbf{1 3 8 . 3}$ \\
Case II & $\mathbf{1 7 0 . 5}$ & $\mathbf{1 4 8 . 2}$ & $\mathbf{1 7 1}$ & $\mathbf{1 7 0 . 5}$ \\
Case III & $\mathbf{1 6 5 . 6}$ & $\mathbf{1 2 9 . 8}$ & $\mathbf{1 6 9 . 8}$ & $\mathbf{1 3 8 . 5}$ \\
Case IV & $\mathbf{1 4 5 . 1}$ & $\mathbf{1 4 1 . 9}$ & $\mathbf{1 4 3 . 2}$ & $\mathbf{1 6 8 . 9}$ \\
Case V & $\mathbf{1 4 0 . 8}$ & $\mathbf{1 2 3 . 3}$ & $\mathbf{1 4 3 . 1}$ & $\mathbf{1 4 1 . 1}$ \\
\hline
\end{tabular}

converter. The main power supply is used for preparing 3000 $\mathrm{W}$ power transferring to the pure resistance load. A data logger with the brand of HBM-Gen ${ }^{3 i}$ is employed for recording onstate voltage of IGBT and diode. Fig. $6 \mathrm{~b}$ shows the main switching cells of the considered DC-DC boost converter for both structures. S2 switch including a MOSFET and power diode as well were both mounted on a separated heat sink in both structures. Five 10uF capacitors are employed in parallel located in series with four high power resistor playing the role of ESR.

Junction temperatures of IGBT and diode have been listed in Table 4 for different cases. Regarding Table 4 , one can find that degradations of IGBT and/or diode can significantly affect their junction temperatures in structure I but not in structure II as the coupling effects point of view. For example, in case III, diode junction temperature increased by $7.2^{\circ} \mathrm{C}$. It means that IGBT aging can directly affect the junction temperature of the power diode leading to more accelerated power diode degradation. However, in structure II in which power switches had been mounted on the separated heat sinks, there are roughly $1^{\circ} \mathrm{C}$ reciprocal deviation in IGBT and diode junction temperatures for IGBT and diode degradations. In addition, in case II in which all the critical components have been degraded and for structure I, IGBT and diode junction temperatures increased by $30.2^{\circ} \mathrm{C}$ and $25.6^{\circ} \mathrm{C}$, respectively leading to much more accelerated aging. It is also the case for structure II. This expresses the importance of IGBT and diode self- and reciprocal-degradations in the coupled thermal systems. It means that in the reliability assessment, this mutual degradation has to be considered which is still lacking in the previous studies.

\section{MODIFIED FRAMEWORK OF RELIABILITY ASSESSMENT OF POWER ELECTRONIC CONVERTERS}

Since reliability of power electronic converters are thoroughly operating-point dependent, consideration of these operating point deviations is paramount of importance which on previous studies are still lacking. Fig. 7 presents the

Fig. 6. Customized DC-DC boost converters. a) Test bench, b) Switching cells. 


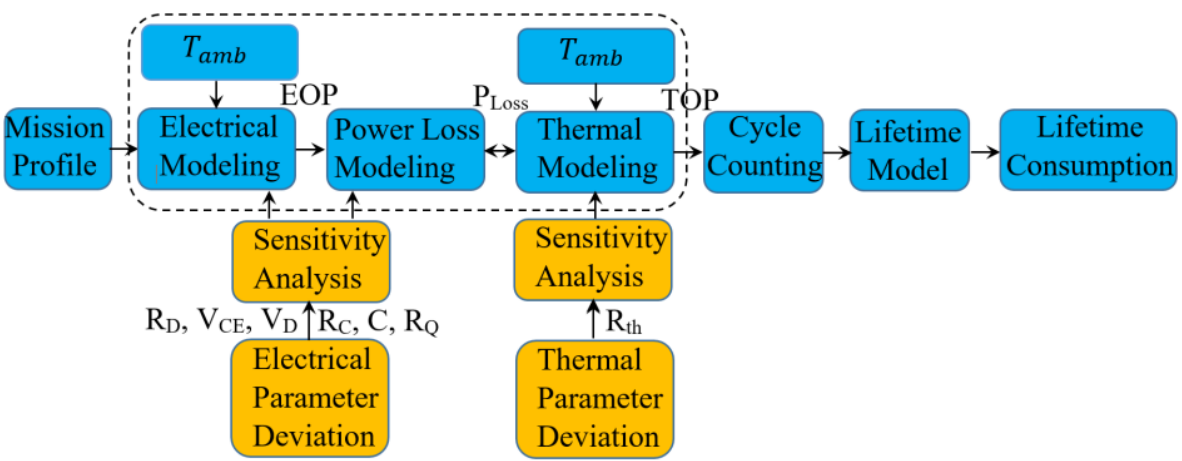

Fig. 7. Newly introduced signal flows and model block diagram to assess the reliability of power electronic converters.

modified conventional framework of reliability assessment in the power electronic converters concentrating on the power semiconductor lifetime model. Power converters are left open to some particular conditions (mission profiles) which are application dependent [20]. These mission profiles should be translated to the electrical parameters e.g. power and voltage. In the second phase, electrical and control modeling of the specified converter should be performed to obtain the electrical operating point. Previously it was mentioned that the root causes of capacitor failure are its voltage and current ripple stresses.

Therefore, an accurate electrical model for analyzing converter either in the open or closed loop is necessary and significant attention must be paid. In another phase, regarding the power semiconductor failure mechanisms and their root cause $\left(T_{j}\right)$, calculating power losses has to be precisely carried out. In addition, an accurate thermal modeling undoubtedly plays a major role in the reliability assessment. For sorting data i.e. $\mathrm{T}_{\mathrm{j}}$ and $\Delta \mathrm{T}_{\mathrm{j}}$ some counting approaches should be employed. Among all the approaches Rainflow counting has been extensively used in power electronic reliability assessment [24]. Then this sorted data is imported to the device lifetime estimation model (e.g. Coffin-Manson [25]) for predicting the useful lifetime. Interval sensitivity analysis has been employed for considering self- and mutual-degradation effects.

\section{LifETIME ESTIMATION}

In the previous sections, it was found that either self or reciprocal degradation of the components can thoroughly affect TOP leading to the decrease of useful lifetime of the critical devices. Therefore, this section deals with lifetime estimation of power semiconductors to express these effects on the components' useful lifetime. As previously mentioned, capacitors are sensitive only to their voltage and current ripple. Since the electrical operating point remained unchanged in this case study (see Table 4), only power semiconductors have been taken into account.

\section{A. Mission profile translation}

The analyzed converter is assumed to be employed in a hybrid electric vehicle as an interface converter between the battery bank and the electrical motor. The considered mission profile is the worldwide harmonized light vehicles test procedure (WLTP-class3) (see Fig. 8) [26]. The mission profile has to be translated to the failure root causes $\left(\mathrm{T}_{\mathrm{j}}\right.$ and $\left.\Delta \mathrm{T}_{\mathrm{j}}\right)$. Therefore, vehicle speed has firstly to be transformed to the required power that will be transferred through the DC-DC power converters:

$$
\mathrm{P}_{\text {conv }}=\frac{\mathrm{B}_{\mathrm{S}} \mathrm{V}}{\eta_{\mathrm{t}}}\left\{\mathrm{Mg}\left(\mathrm{f}_{\mathrm{r}}+\mathrm{i}\right)+\frac{1}{2} \rho_{\mathrm{a}} \mathrm{C}_{\mathrm{D}} \mathrm{A}_{\mathrm{f}} \mathrm{V}^{2}+\mathrm{M} \delta \frac{\mathrm{dV}}{\mathrm{dt}}\right\}+\mathrm{P}_{\text {aux }}
$$

The parameters have been defined in [24] and $\mathrm{P}_{\text {aux }}$ is 100W for auxiliary equipment.

The next step is to translate the transferred power to the failure root causes (see the dashed-line border in Fig. 7). This procedure has been done via using electrical, power loss and thermal modeling in the first four cases of structures I and II for every point in the mission profile. As an example, Fig.9 shows the IGBT junction temperature in structure I for cases II-IV. By IGBT and diode aging (case II-IV), junction temperature of devices increase in comparison with new ones (case I).

\section{B. Lifetime estimation}

Regarding critical failure mechanisms, the well accepted law, namely Arrhenius-Coffin-Manson, is employed in this study [27]. In addition, a degradation model can be assessed assuming linear degradation accumulation (Miner's rule) [27]-[29]. The lifetime estimation methodology is described in detail in [30].

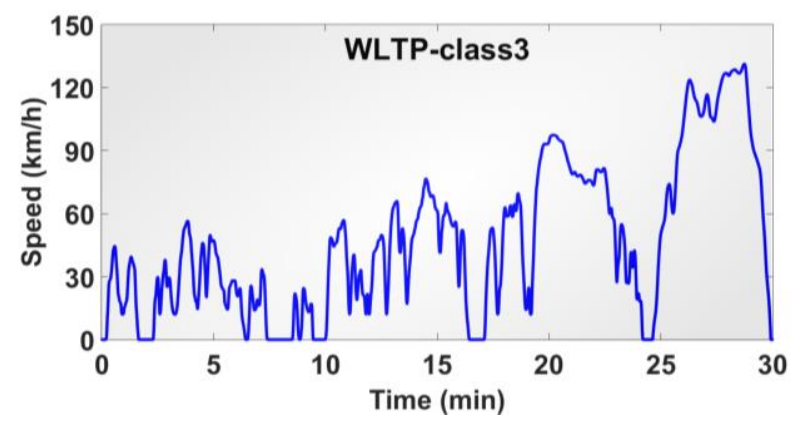

Fig. 8. WLTP-class3 driving cycle.

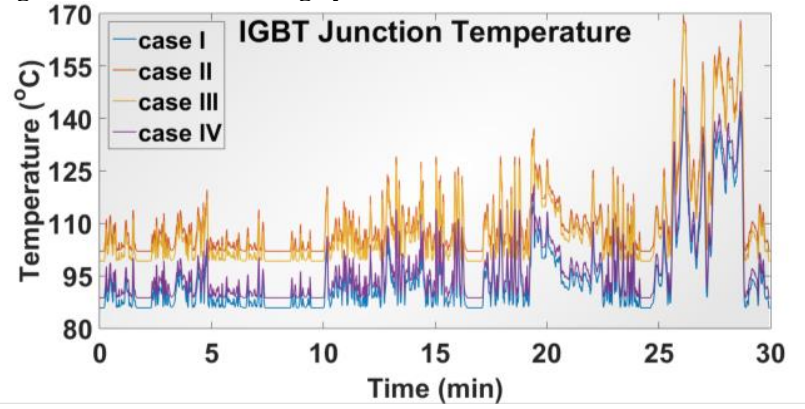

Fig. 9. Junction temperature of IGBT in case I-IV. 
Arrhenius-Coffin-Manson's lifetime model expresses the number of cycles before the failure in terms of mean temperature and amplitude of junction temperature swings as:

$$
\mathrm{N}_{\mathrm{f}}\left(\mathrm{T}_{\mathrm{m}}, \Delta \mathrm{T}_{\mathrm{j}}\right)=\mathrm{A} \times \Delta \mathrm{T}_{\mathrm{j}}^{\alpha} \times \exp \left(\mathrm{Q} / \mathrm{RT}_{\mathrm{m}}\right)
$$

where $\mathrm{A}, \alpha$ are both constant and device-dependent, $\mathrm{R}$ and $\mathrm{Q}$ are the gas constant $\left(8.314 \mathrm{JMol}^{-1} \cdot \mathrm{K}^{-1}\right)$ and internal energy and $\mathrm{T}_{\mathrm{m}}$ is the mean junction temperature of devices in Kelvin. $\Delta \mathrm{T}_{\mathrm{j}}$ expresses the junction temperature swing of devices. Based on the performed accelerated power cycling (APC) test and using least square curve fitting to that of (7), one can find that $\alpha=-1.117, \mathrm{~A}=4.352 \times 10^{3}$ and $\mathrm{Q}=1.8523 \times 10^{4}$ for IGBT and $\alpha=-1.128, \mathrm{~A}=4.093 \times 10^{3}$ and $\mathrm{Q}=1.8604 \times 10^{4}$ for diode. Number of cycles to failure for IGBT and diode are shown in Fig. 10. The tests were performed for 32 IGBTs and 32 diodes.
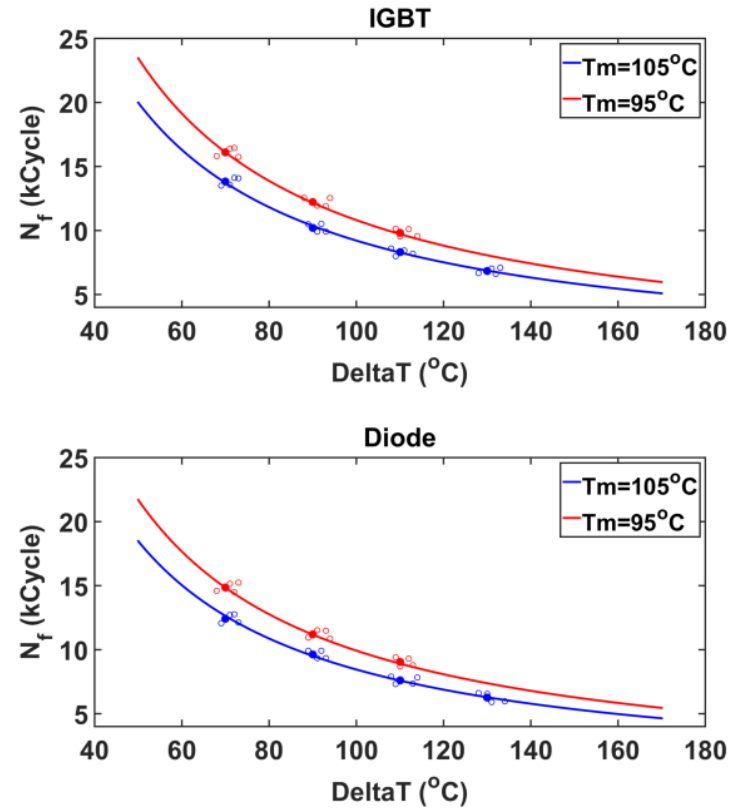

Fig. 10. Number of cycles to failure of IGBTs and diodes exposed to APC test.

Linear damage accumulation, Miner's rule has been used for evaluating the useful time of IGBT and diode [27],

$$
\mathrm{D}=\sum \mathrm{N}\left(\mathrm{T}_{\mathrm{m}}, \Delta \mathrm{T}_{\mathrm{j}}\right) / \mathrm{N}_{\mathrm{f}}\left(\mathrm{T}_{\mathrm{m}}, \Delta \mathrm{T}_{\mathrm{j}}\right)
$$

Regarding the mission profile and employing (7) and (8), useful lifetimes of IGBT and diode in all four cases both in structures I and II are listed in Table 5. By device aging (either IGBT or diode) lifetimes of IGBT and diode significantly changed. Therefore, considering either component self- or reciprocalaging in lifetime estimation is paramount of importance.

Regarding Table. 5, in structure I while only IGBT is aged (case III), the useful lifetime of diode decreases by 6796 hours (30\%). In diode aging case (case IV), the useful lifetime of IGBT decreases by 1511 hours (8.3\%). Accordingly, reciprocal effects on lifetime of devices become apparent. In structure II, single aging of IGBT and diode does not have any considerable effects on each other degradation owing to thermal decoupled system.

In structure I and in case II in which both IGBT and diode are aged, the lifetime decreases are 6431 and 9725 hours for IGBT and diode respectively (affected by both self- and reciprocaldegradation). In structure II in which it was predicted that reciprocal effects are not significant, lifetime decreases (due to the self-degradation) are 6766 and 6596 hours for IGBT and diode respectively.

Accordingly, regarding the useful lifetime of devices in cases I and II (in both structures), there will be a range for lifetime of devices that should be taken into account in the reliability assessment. For example in structure I, the weakest device is IGBT. The IGBT useful lifetime put between 18197 hours 11766 hours from new device to aged device. Therefore, this bound has to be considered in reliability assessment of power converters.

\begin{tabular}{ccccc}
\multicolumn{2}{c}{ Table 5. Useful Lifetime of Devices (hours) } \\
\hline \hline \multirow{2}{*}{ Case } & \multicolumn{2}{c}{ Structure I } & \multicolumn{2}{c}{ Structure II } \\
\cline { 2 - 5 } & IGBT & Diode & IGBT & Diode \\
\hline Case I $($ New $)$ & 18197 & 22168 & 18020 & 18014 \\
Case II $($ Aged $)$ & 11766 & 12443 & 11254 & 11424 \\
Case III $($ IGBT Aged) & 12882 & 15372 & 11475 & 18014 \\
Case IV (Diode Aged) & 16686 & 18313 & 17841 & 11424 \\
\hline
\end{tabular}

\section{CONCLUSION}

In this paper the self and reciprocal effects of components' degradations on each other has been thoroughly discussed. It is found that self and reciprocal components' degradation can thoroughly affect the system thermal operating point and subsequently the system reliability. Accordingly, these dependencies have to be considered in the reliability assessment. The new framework of converters reliability assessment has been introduced. A DC-DC boost converter has been presented as a case study to express the importance of this new reliability assessment. It is shown that in this case study, the impact of the capacitor had not any influence on the semiconductor devices. However, depending on the cooling structure, the reciprocal effects on the semiconductor devices are thoroughly important and significant. Then, through a detailed loss and thermal modeling, the lifetime calculation is really impacted by the reciprocal effects. Experimental verification of reciprocal and self-degradation effects are being worked to be implemented and reported in near future.

\section{REFERENCES}

[1] Y. Song and B. Wang, "Survey on Reliability of Power Electronic Systems," in IEEE Transactions on Power Electronics, vol. 28, no. 1, pp. 591-604, Jan. 2013.

[2] H. Wang, M. Liserre and F. Blaabjerg, "Toward Reliable Power Electronics: Challenges, Design Tools, and Opportunities," in IEEE Industrial Electronics Magazine, vol. 7, no. 2, pp. 17-26, June 2013.

[3] H. Wang, M. Liserre, F. Blaabjerg, P. de Place Rimmen, J. B. Jacobsen, T. Kvisgaard, and J. Landkildehus, "Transitioning to Physics-of-Failure as a Reliability Driver in Power Electronics," IEEE Trans. Emerg. Sel. Topics Power Electron., vol. 2, no. 1, pp. 97-114, March 2014.

[4] S. Yang, A. Bryant, P. Mawby, D. Xiang, L. Ran and P. Tavner, "An Industry-Based Survey of Reliability in Power Electronic Converters," in IEEE Transactions on Industry Applications, vol. 47, no. 3, pp. 14411451, May-June 2011

[5] H. Wang, K. Ma and F. Blaabjerg, "Design for reliability of power electronic systems," IECON 2012 - 38th Annual Conference on IEEE Industrial Electronics Society, Montreal, QC, 2012, pp. 33-44.

[6] J. Gu, N. Vichare, T. Tracy and M. Pocht, "Prognostics Implementation Methods for Electronics," 2007 Annual Reliability and Maintainability Symposium, Orlando, FL, 2007, pp. 101-106.

[7] Y. Avenas, L. Dupont, N. Baker, H. Zara and F. Barruel, "Condition Monitoring: A Decade of Proposed Techniques," in IEEE Industrial Electronics Magazine, vol. 9, no. 4, pp. 22-36, Dec. 2015.

[8] M. Musallam, C. Yin, C. Bailey and M. Johnson, "Mission Profile-Based Reliability Design and Real-Time Life Consumption Estimation in 
Power Electronics," in IEEE Transactions on Power Electronics, vol. 30, no. 5, pp. 2601-2613, May 2015.

[9] C. Durand, M. Klingler, D. Coutellier and H. Naceur, "Power Cycling Reliability of Power Module: A Survey," in IEEE Transactions on Device and Materials Reliability, vol. 16, no. 1, pp. 80-97, March 2016.

[10] H. Wang and F. Blaabjerg, "Reliability of Capacitors for DC-Link Applications in Power Electronic Converters-An Overview," in IEEE Transactions on Industry Applications, vol. 50, no. 5, pp. 3569-3578, Sept.-Oct. 2014.

[11] Samavatian, V., Avenas, Y., \& Iman-Eini, H. (2018). Mutual and selfaging effects of power semiconductors on the thermal behaviour of DCDC boost power converter. Microelectronics Reliability, 88, 493-499.

[12] P. Ghimire, S. Bęczkowski, S. Munk-Nielsen, B. Rannestad and P. B. Thøgersen, "A review on real time physical measurement techniques and their attempt to predict wear-out status of IGBT," 2013 15th European Conference on Power Electronics and Applications (EPE), Lille, 2013, pp. 1-10.

[13] Lutz, J., H. Schlangenotto, and U. Scheuermann. "Semiconductor Power Devices Physics, Characteristics, Reliability. 3-10." (2011).

[14] J.W. Kimball, P. T. Krein, and P. T., "Singular perturbation theory forDC-DC converters and application to PFC converters," IEEE Trans. Power Electron., vol. 23, no. 6, pp. 2970-2981, Nov. 2008.

[15] Y. Chen, A. Davoudi, and P. L. Chapman, "Multi frequency modeling of a multiple-input dc-dc converter," in Proc. IEEE Power Electron. Specialists Conf., 2008, pp. 4604-4610.

[16] H. Behjati, L. Niu, A. Davoudi and P. L. Chapman, "Alternative TimeInvariant Multi-Frequency Modeling of PWM DC-DC Converters," in IEEE Transactions on Circuits and Systems I: Regular Papers, vol. 60, no. 11, pp. 3069-3079, Nov. 2013.

[17] Bing Gao, Fan Yang, Minyou Chen, Li Ran, Irfan Ullah, Shengyou Xu, Philip Mawby, "A Temperature Gradient-Based Potential Defects Identification Method for IGBT Module", Power Electronics IEEE Transactions on, vol. 32, pp. 2227-2242, 2017.

[18] M. J. Whitehead and C. M. Johnson, "Junction Temperature Elevation as a Result of Thermal Cross Coupling in a Multi-Device Power Electronic Module," 2006 1st Electronic System integration Technology Conference, Dresden, 2006, pp. 1218-1223.

[19] M. Musallam and C. M. Johnson, "Real-Time Compact Thermal Models for Health Management of Power Electronics," in IEEE Transactions on Power Electronics, vol. 25, no. 6, pp. 1416-1425, June 2010.

[20] A. S. Bahman, K. Ma, and F. Blaabjerg, "Thermal impedance model of high power IGBT modules considering heat coupling effects," in Proc. Electron. App. Conf. Expo., 2014, pp.1382-1387.

[21] T. Ding et al., "How affine arithmetic helps beat uncertainties in electrical systems," IEEE Circuits Syst. Mag., vol. 15, no. 4, pp. 70- 79, Fourthquarter 2015.

[22] R. Moore et al., Introduction To Interval Analysis. Philadelphia, PA, USA: Soc. Ind. Appl. Math., 2009.

[23] M. Althoff et al., "Analyzing reachability of linear dynamic systems with parametric uncertainties," in Modeling, Design, and Simulation of Systems with Uncertainties, A. Rauh and E. Auer, Eds. Berlin Heidelberg: Springer, May 2011, pp. 69-94.

[24] Samavatian, V., Iman-Eini, H., \& Avenas, Y. (2018). An efficient online time-temperature-dependent creep-fatigue rainflow counting algorithm. International Journal of Fatigue, 116, 284-292.

[25] C. Busca, R. Teodorescu, F. Blaabjerg, S . Munk-Nielsen, L. Helle, T. Abeyasekera and P. Rodriguez, "An overview of the reliability prediction related aspects of high power IGBTs in wind power applications," Journal of Microelectronics Reliability, vol. 51 , no. 9-11, pp. 1903-1907, 2011.

[26] D. I. Stroe, M. Swierczynski, S. K. Kær, E. M. Laserna and E. S. Zabala, "Accelerated aging of Lithium-ion batteries based on electric vehicle mission profile 2017 IEEE Energy Conversion Congress and Exposition (ECCE), Cincinnati, OH, 2017, pp. 5631-5637.

[27] P. Held, G. Jacob, P. Nicoletti, P. Scacco, and M.-H. Pooch, "Fast power cycling test for IGBT modules in traction application," in Proc. Power Electron. Drive Syst., 1997, pp. 425-430.

[28] A. T. Bryant, P. A. Mawby, P. R. Palmer, E. Santi, and J. L. Hudgins "Exploration of power device reliability using compact device models and fast electro-thermal simulation," in Conf. Rec. IEEE IAS Annu. Meeting, Tampa, FL, USA, Oct. 2006, vol. 3, pp. 1465-1478.

[29] M. Mussallam and C. M. Johnson, "An efficient implementation of the rainflow counting algorithm for life consumption estimation," IEEE Trans. Reliab., vol. 61, no. 4, pp. 978-986, Dec. 2012.
[30] L. GopiReddy, L. M. Tolbert, and B. Ozpineci, "Lifetime prediction of IGBT in a STATCOM using modified-graphical rainflow counting algorithm," in Proc. Annu. Conf. IEEE Ind. Electron. Soc., Montreal, QC, Canada, Oct. 25-29, 2012, pp. 3425-3430.

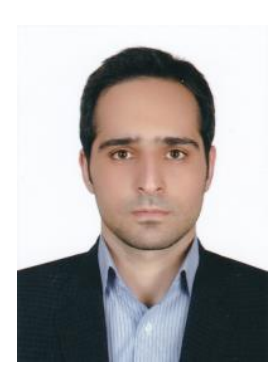

Vahid Samavatian received the B.S. degree from the Islamic Azad University-South Tehran Branch, Tehran, in 2012, the M.S. degree from the Khajeh Nasir University of Technology, Tehran, in 2014 and the Ph.D. degree jointly from the University of Tehran, Tehran, Iran and the 'Communauté Université Grenoble Alpes', Grenoble, France in 2019, all in electrical engineering. Since then, he has been a postdoctoral researcher at the Sharif University of Technology, Tehran, Iran. His research interests include reliability evaluation of power electronic systems, power electronics cooling, physics of failure of power devices and power electronics condition monitoring.

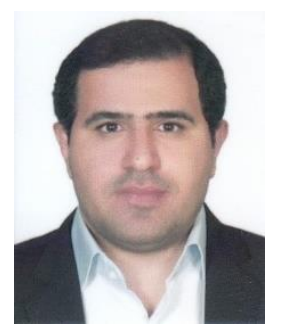

Hossein Iman-Eini (M'10-SM'17) received the B.S. and M.S. degrees from the University of Tehran, Tehran, Iran, in 2001 and 2003, respectively, and the $\mathrm{Ph} . \mathrm{D}$. degree jointly from the University of Tehran and the Grenoble INP, Grenoble, France, in 2009, all in electrical engineering. He is currently an Associate Professor with the School of Electrical and Computer Engineering, College of Engineering, University of Tehran. His current research interests include the modeling and control of power converters, renewable energy systems, and applications of power electronics in power systems.

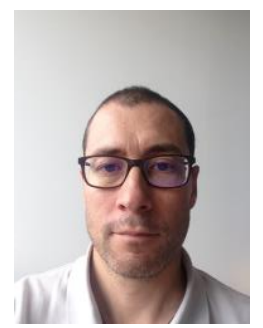

Yvan Avenas (yvan.avenas@grenoble-inp.fr) is Assistant Professor at Grenoble Institute of Technology (France) since 2005. He received the $\mathrm{PhD}$ degree from the 'Institut Polytechnique de Grenoble' (INPG) in Grenoble, France, in 2002. He carries out his research activities in Grenoble Electrical Engineering Lab (G2Elab) and is co-head of the power electronics group since 2015 . He works on thermal management and 3D packaging of power electronics. He is also interested in thermal characterization of power semiconductor devices.

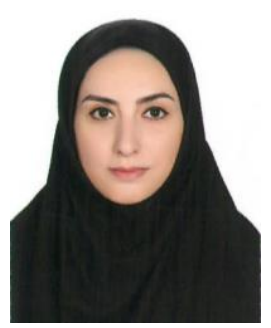

Soudabeh Shemehsavar received the B.S degree from Shiraz University, Shiraz, Iran, in 1997, the M.S. degree from Amirkabir University of Technology, Tehran, Iran, in 2000 and the Ph.D. degree from Amirkabir University of Technology, Tehran, Iran, in 2007, all in Statistics. She is currently Assistant Professor with the School of Mathematics, Statistics and Computer Science, University of Tehran. Her current research interests include reliability, maintenance, stochastic process and their application in biology and Poisson-Dirichlet process and its generalization. 